\title{
The Impact Of Internal Organizational Factors On The Inappropriate Job Performance And Behaviour Of Employees: A Case Study
}

Prakash Singh, Nelson Mandela Metropolitan University, South Africa Thembinkosi Twalo, Human Sciences Research Council, South Africa

\begin{abstract}
The focus of this paper is on the impact of internal organizational factors on the inappropriate job performance and behaviour of employees. The Buffalo City Metropolitan Municipality (BCMM) in South Africa has been experiencing inappropriate job behaviour and performance of some of its workers. They include misappropriation of resources, maladministration, mismanagement, lack of service delivery, fraud, and corruption. Since many BCMM workers have various levels of formal education, such practices are not expected, because the structural-functionalist assumption is that formal education is a solution to societal challenges. Since inappropriate job behaviour and performance continue to be reported in spite of the formal education of BCMM workers, this study seeks to investigate how the two phenomena co-exist. It thus seeks to put into perspective the paradoxical co-existence of formal education with inappropriate job behaviour and performance, by focusing on the BCMM as a case-study.
\end{abstract}

For data collection, this study used the mixed method approach; that is, a combination of qualitative and quantitative methods. The findings revealed structural, systemic, and human impediments to labour productivity in the BCMM. By and large, the unquestioning acceptance of the assumption that the skills shortage is responsible for inappropriate workers' job performance and behaviour is discredited by the evidence of skilled personnel who exercise their responsibilities in a manner that undermines their occupational requirements. Therefore, this exploratory study affirms that the narrow conception of skills, that privileges job-specific capabilities, is not enough for cultivating a workforce with appropriate job behaviour and performance practices.

Keywords: Structural Functionalism; Skills Shortage; Inappropriate Job Performance and Behaviour; Job Satisfaction

\section{INTRODUCTION}



he focus of this paper is on the impact of internal organizational factors on the inappropriate job performance and behaviour of employees. It is based on a case study of the BCMM because the BCMM's ability to cope with its responsibilities has been called into question by reports of poor administration; weak management of finances, human resources, and assets; inappropriate job performance and behaviour by some municipal workers and other challenges (Nombembe, 2013; Coetzer, 2009; Times Live, 2011). Such claims appear regularly in the media and further evidence is available from various sources like audit reports, parliamentary discussions, reports to parliament, and municipal and departmental reports (Nini, 2012; Nombembe, 2013). 
Paradoxically, inappropriate job behaviour and performance practices have been taking place, although many BCMM workers have formal educational qualifications. Structural-functionalists perceive formal education as one of the factors that curb inappropriate job behaviour and performance in the attempt to achieve stability and consensus in society (Bryant, 2012; Guerrero, 2005; Haralambos \& Heald, 1985; Moore \& Moore, 1982; Almquist, Chafetz, Chance, \& CorderBolz, 1978). In light of the structural-functionalist assumption that formal education is a solution to societal challenges, inappropriate job behaviour, and performance at the BCMM is unexpected. The expectation is rather that formal education should help obviate such problems (Labaree, 2008). Since inappropriate job behaviour and performance continue to be reported in spite of the formal education of BCMM workers, this study seeks to investigate how the two phenomena co-exist. It thus seeks to put into perspective the paradoxical coexistence of formal education with inappropriate job behaviour and performance, by focusing on the BCMM as a case-study.

\section{PARADOXICAL CO-EXISTENCE OF FORMAL EDUCATION WITH INAPPROPRIATE JOB BEHAVIOUR AND PERFORMANCE AT THE BCMM}

The functional analysis of society is called functionalism or structural functionalism (Gerber, 2010; Cliff, 2012) and these terms are used interchangeably in this paper. The functionalist argument is that the purpose of education is to solve societal problems (Bryant, 2012; Guerrero, 2005; Haralambos \& Heald, 1985; Moore \& Moore, 1982). In light of the functionalist argument, the problem this study investigates is how is it possible for the BCMM to experience perpetual inappropriate job behaviour and performance when many BCMM workers have academic credentials. This paradox is central in this study because it questions the assumption that workers with formal education make a significant contribution in addressing the country's societal challenges, yet the BCMM experiences significant challenges from workers with formal education. While the assumption is not negated, this study draws attention to the evidence of workers with formal education who cause significant societal challenges. This study assumes that this is due to the over-emphasis of one component of skill, namely, job-specific skills, at the expense of others such as appropriate attitudes, values and ethics. This has created a favourable environment for the proliferation of BCMM workers' inappropriate job behaviour and performance challenges. The study then assumes that the application of broad skills could counter this challenge effectively and lead to more appropriate job behaviour and performance at the BCMM.

The co-existence of formal education with inappropriate job behaviour and performance raises questions about the effectiveness of the BCMM's performance management systems (Badat, 2009; Badenhorst, 2012; Local Government Handbook, 2012). Structural-functionalists assume that formal education is one of the factors that curb inappropriate job behaviour and performance in an effort to achieve stability and consensus in society (Bryant, 2012; Guerrero, 2005; Haralambos \& Heald, 1985; Moore \& Moore, 1982; Almquist et al., 1978). Durkheim (1977) believes that the major function of education is the transmission of society's norms and values, a system through which pupils would come to learn that it is wrong to act against the interests of the social group as a whole. If education serves this function, amongst others, then a question arises: How is it possible for some BCMM workers' job behaviour and performance to undermine the interests of the BCMM community when most of the workers have formal education? Inappropriate job behaviour and performance in the BCMM evokes what Plato, Aristotle, and Locke (Naugle, 2001; Cahn, 1970) tried to resolve as they probed how it was possible for people who have been taught what is right to act contrary to the principles they have learned. This shows that this has been a concern for centuries; it has now been manifested in the BCMM through the workers' inappropriate job behaviour and performance. It is for this reason that this study investigates the co-existence of formal education with inappropriate job behaviour and performance at the BCMM to attempt to establish what makes this possible.

Various inappropriate job behaviour and performance practices permeate society and are manifested in the public and private sectors (Goss, 1994; Public Protector South Africa, 2012; van Heerden, 2010; Agrawal \& Cooper, 2007). These practices range from simple to complex, erroneous to purposeful, and the role players include government employees, private citizens, and organizsations. Furthermore, the ripple effect is severe, because these practices exacerbate poverty and under-development. With regard to corruption, for instance, money that could have been used for service delivery, poverty relief, community development, education, health, crime prevention, and other socially useful purposes gets spent by a few individuals mostly on non-essential expenses (Greenburg, 2002; Mawonga, 2012; Benya, 2011). On the basis of the seriousness of this challenge, this study attempts to understand 
the inappropriate job behaviour and performance phenomenon so as to be able to propose possible solutions. It hypothesises that this phenomenon at the BCMM is attributable to the paucity of the various dimensions of knowledge ('know that', 'know why', 'know how') as well as attitudes, ethics and values (Hanushek \& Woessmann, 2008). Testing this hypothesis requires a proper examination of broad skills in order to determine which of the components of broad skills is not being applied by the workers and it also requires identification of gaps in the BCMM management system which make it possible for this phenomenon to exist (Badat, 2009; Local Government Handbook, 2012).

It is important to emphasise that though this study hypothesises that inappropriate job behaviour and performance in the BCMM is due to the paucity of broad skills, it does not downplay the importance of formal education. The importance of formal education in the BCMM is unquestionable as it is crucial for enhancing economic growth, social development, and other municipal objectives. However, the hypothesis suggests that the uncritical acceptance of formal education as a panacea for socio-economic challenges translates to a failure to critically analyse the skills required to undertake a particular task. Skills acquired through formal education are narrow in nature as they predominantly enhance job-specific capabilities and only to a lesser extent enhance crucial elements that contribute to quality work performance, such as ethics, values, and attitudes. Similarly, skills acquired through socialisation or background are also narrow in nature as they predominantly enhance interpersonal skills, communication, responsibility, integrity, empathy, teamwork, sociability and the like (Gerber, 2009). However, the recognition of the various forms of narrow skill acquired through schooling, socialisation, culture, background, and otherwise, translates to the notion of broad skills. The notion of broad skills involves the idea that labour (ability to do a job) is a product of many varied elements and is determined by the total human being (Bourdieu, 1997; Badat, 2009). For this reason, Gichure (2000) notes that because it is an activity, work requires some effort for its accomplishment seeing that "work, as a human activity requires intentionality and voluntariness" (p. 3).

\section{METHODOLOGY}

This study used the mixed method approach, that is, a combination of qualitative and quantitative methods (Creswell \& Plano-Clark, 2007). The investigation merited a mixed methods approach because of the complexity of the notion of broad skills, some of whose components are immeasurable, unobservable, and unquantifiable. Mixing the qualitative and quantitative data helped to provide a better understanding of the municipal workers' job behaviour and performance at the BCMM since limited data would have been collected if either method had been used. Qualitative methods included an analysis of relevant literature, semi-structured interviews with sampled workers from various departments and in different ranks. The quantitative method was in the form of a questionnaire with 79 closed-ended questions, which included 10 biographical questions. The questionnaire had 6 qualitative questions; thus the total number of questions was 85 . BCMM workers were requested to complete and return the questionnaire that was sent to them by email and fax, and later hand delivered.

As of 30 June 2012, the BCMM had 8 directorates, 39 departments, and a total staff complement of 5,427 (Buffalo City Metropolitan Municipality, 2012). Ten respondents per department were meant to be sampled for responding to the questionnaire, so as to have 390 respondents in total. For the structured interviews, 1 person was meant to be sampled per directorate, so as to have 8 interviewees in total. However, due to fieldwork logistics that included a high rate of refusal to participate in some departments, the share of respondents per department could not be balanced. Consequently, some departments were over-represented and others were under-represented. In lieu of getting 398 respondents ( $7 \%$ of the total staff complement), only 342 (6\% of the total staff complement) could participate. However, physically administering the questionnaire around the BCMM offices meant that the respondents were much more than 342. This is because the researcher had to explain to the workers what the questionnaire was about and, in return, they spoke about their experiences and observations at the BCMM, including those who refused to complete the questionnaire. The refusal to complete the questionnaire was on account of lack of time by some workers, fear of victimisation because the environment was highly political, and research fatigue by those who felt that they had participated in too many research projects, yet nothing seemed to change.

The questions in the questionnaire and interview questions were formulated in such a way that they adhere to the study's conceptual framework, the amalgamation of human capital, social capital, cultural capital, and reputation capital. Purposeful sampling was made since special attention had to be paid to staff with formal 
education in order to investigate the co-existence of formal education with inappropriate job behaviour and performance. However, many workers $(49 \%)$ had no matric and most of them were in elementary occupations (Buffalo City Metropolitan Municipality, 2011a), so the formal education prerequisite of the participants had to take this into consideration. The level of formal education was not made a prerequisite because most workers' education level was commensurate with their occupations. Taking these technicalities into consideration, the research questions then sought to probe how inappropriate job behaviour and performance persisted in the respective occupations despite the commensurate education credentials.

The research process and instruments were designed to enable meaningful analysis of the data, because on its own, data is meaningless unless systematically and logically interpreted. This interpretation was done through analysis of the responses against relevant laws and policies such as the Municipal Structures Act (1998), The Local Government Municipal Systems Act (2000), BCMM supply chain management (SCM) policy and recruitment policy. For the quantitative data analysis, empirical statistical data were generated and processed by a qualified statistician from the Nelson Mandela Metropolitan University's (NMMU's) Statistics Department. Non-parametric statistical tests were conducted using SPSS version 12.0 programmes to analyse the relationships between variables. The Spearman rank correlation coefficient was used to determine the relationship between categorical variables. Non-parametric statistical methods are also called parameter-free or distribution-free methods because they rely on classification, ranking or order rather than numbers because the researcher is not in a position to give a numerical description of the population (Business Dictionary, 2013; Investopedia, 2013).

The statistical significance of the variables' correlation was calculated using the chi-square test and crosstabulations of the data. For each cross-tabulation, the chi-square test is reported that indicates statistical significance, Cramer's V is also reported that indicates the practical significance (small, medium, or large), and lastly Spearman rank correlation is also reported since the variables are ordinal. Since the instruments sought to determine the opinions of the respondents, ordinal scales were used since they are "measures of non-numeric concepts like satisfaction, happiness and discomfort" (My Market Research Methods, 2012, p. 1). For measuring the internal consistency (reliability) of the instrument, Cronbach's alpha was used. The levels of reliability appeared to be high with an average of 0.75 for employees' job behaviour and an average of 0.82 for employees' job performance.

Participation in this study was voluntary and all participants were made aware of this through the covering letter. Their confidentiality was also promised with the covering letter undertaking that participants' personal details would not be disclosed under any circumstances. There would therefore be no risk of harm, embarrassment, or offence to any participant or to the municipality. In fact, the biographical information section enabled them to remain anonymous since the required information was about their directorates and departments, type of employment, tenure, and educational qualifications. The covering letter also noted that there were no risks or discomforts associated with participation. It also clearly stated that there were no pecuniary benefits of participation to the participants, although the study would be very helpful in supporting policy changes that would help in addressing the broad skills shortage challenge. Participants' attention was also drawn to the fact that this research was approved by the university's Research Ethics Committee, with ethics approval number H12-EDU-ERE-028. They were assured that this committee is competent, being composed of experts whose responsibility includes ensuring that the rights and welfare of participants in this study are protected and that the study is conducted in an ethical way.

\section{DISCUSSION OF FINDINGS}

The responses indicate that some managers struggle to exercise control in their respective departments due to internal factors. Many people in BCMM management are in acting positions. They hope for permanent appointment, which they believe depends on pleasing the relevant stakeholders. One respondent refers to the BCMM as "Hollywood because everyone is acting in a position they are still studying to be in or on sick leave. BCMM is an extended wing of St Mark's Hospital." The acting capacity of many workers renders them indecisive when tough and unpopular decisions have to be taken. For instance, some respondents suggest that a line manager may follow all procedures for dealing with poorly performing and/or inappropriately behaving workers, but when managers exhaust the applicable corrective measures without achieving the desired outcomes, then punitive ones should be used. This may include sacking the workers in question. However, the municipal manager as the accounting officer of the 
municipality has the authority to hire and fire workers after all proper procedures have been followed. Since all municipal managers were in acting positions from November 2008 to March 2012 when the current municipal manager was appointed permanently, they did not want to jeopardise their chances of permanent employment in this position. Consequently, they usually refused to fire poorly performing and inappropriately behaving workers. Instead, they asked the manager concerned, who has no authority to fire anyone, to deal with the matter, thereby expecting him or her to use corrective measures indefinitely. This compromises management authority and under such circumstances, some workers may take advantage of the environment because they know that no negative consequences will follow their inappropriate job behaviour and performance.

Despite the challenges with acting municipal managers, it is important to note that the enforcement of disciplinary measures is not solely this official's responsibility. According to the BCMM Key Performance Indicators (KPA) Achievement Report (2011a), the Labour Relations Division of the Human Resources Department "is responsible for employment relations and maintenance of discipline at the workplace" (p. 36). The report further notes that the responsibility of the Labour Relations Division also includes ensuring that line managers are capacitated in all aspects of labour relations so as to be able to exercise control and diligently discharge their duties. The Labour Relations Division also ensures the implementation and enforcement of the collective agreement disciplinary code. Consequently, "during the 2010/11 financial year a total of one hundred and forty six (146) disciplinary hearings was conducted and thirty one (31) suspension cases and disciplinary enquiries were handled and finalised" (Buffalo City Metropolitan Municipality, 2011a, p. 36). Of the 86 submitted grievances, 33 were resolved (Ibid.). To prevent further occurrences of job misbehaviour, the Labour Relations Division conducted road shows to educate workers about expected job behaviour and made them aware of the common misdemeanours that lead to punitive measures against offenders.

It is important to note that 146 disciplinary hearings were conducted in the 2010/11 financial year, that is, when the municipality still had an acting manager. This challenges the suggestion that there was indecisiveness which translated to inaction against offending workers. The collective decision-making process in the disciplinary hearings may have assisted in this regard, mitigating the effects of punitive decision making by managers who are in acting positions. Furthermore, the Local Government Municipal Systems Act (2000) requires municipalities to "take measures to prevent corruption" (p. 22). It is commendable that the BCMM is acting against job misdemeanours such as fraud and corruption as evidenced by the suspensions, dismissals, and issuing of written warnings to misbehaving workers. However, BCMM measures to prevent corruption seem to be under threat. Expanding on the question, "Does the BCMM have an effective policy to get rid of unproductive workers?" one respondent argued that the BCMM does not have such a policy:

The only policy this place has is to try and get rid of good people and cover up corruption. Take the City Manager, he points out the wrong doings of all ..., suddenly he is in the firing line, wonder why, maybe because tenders are not going the way they used to and the CM [City Manager] knows how to say no. BCMM IS CORRUPT TO THE CORE [sic].

It also transpired that some BCMM councillors were accused of corruption, even though the Local Government Municipal Systems Act (2000) states that a councillor must "perform the functions of the office in good faith, honestly, and in a transparent manner; and at all times act in the best interest of the municipality and in such a way that the credibility and integrity of the municipality are not compromised" (p. 106). To curb corruption, the requirements of the Act need to be applied. The same Act (2000) requires the municipality, in accordance with the Employment Equity Act (1998) to develop and adopt appropriate systems and procedures to ensure fair, efficient, effective, and transparent personnel administration, including (a) the recruitment, selection, and appointment of persons as staff members; (b) the supervision and management of staff; and (c) the monitoring, measuring, and evaluating of performance of staff.

The Local Government Municipal Systems Act (2000,) requires that there be "a culture of public service and accountability amongst staff" (p. 22). It is, however, difficult to know whether this has been achieved at the BCMM because most of the respondents (53\%) are neutral on the question about whether workers are mindful of the impact of their actions on others. However, $38 \%$ believe that the workers were mindful while only $9 \%$ felt that they were not. With regard to whether workers cared if others suffered as a result of them doing their jobs badly, $34 \%$ of 
the respondents agreed, 36\% dissented, and 30\% were neutral. In terms of the same Local Government Municipal Systems Act (2000), the code of conduct for municipal staff members requires them to "foster a culture of commitment to serving the public" (p. 114). However, while $31 \%$ of respondents observed that the quality of service discourages customers from dealing with the BCMM again, 37\% thought it does not. This shows that more still needs to be done at the BCMM in line with Section 95 of the Local Government Municipal Systems Act (2000) which seeks to "establish a sound customer management system that aims to create a positive and reciprocal relationship between persons liable for payments, and the municipality" (SALGA, 2011, p. 9).

Responding to the question as to why some workers engage in inappropriate job behaviour and performance practices, although they have formal educational qualifications, one respondent stressed that:

It is because there is no or little communication with the management of all relevant policies and procedures when employees are newly employed in BCMM. Management is inconsistent in the application of such policies. It depends whether the manager likes or dislikes you and that will determine the outcome of the specific issue. Staff who outshine, and go the extra mile in their work are not recognised as there is no performance management system in place, so employees just come and do "that much" and go home, whether it's in line with policy or not, who cares. Lack of genuine care, respect, trust and positivity for each other has greatly diminished and the spirit of Ubuntu is almost dead. Management too don't comply with the policies, they are just there in black and white, but few if any comply with or review such policies. I think for unskilled or semi-skilled employees, it could be that they are less educated and need someone to educate them in their mother tongue about the repercussions of non-compliance.

According to $88 \%$ of respondents, some workers know what is right, but still do what is wrong indicates shortage not of narrow, but of broad skills. In fact, evidence suggests that human nature and the work environment could be fuelling inappropriate job behaviour and performance. Hence, Singh's (2011) caution that "the human factor is not secondary" to the labour process (p. 498). As 52\% of respondents have no opinion in this regard, while $34 \%$ think that they are consistent and 8\% think they are not, it is difficult to ascertain if the policies and practices in the BCMM are consistent in addressing unethical conduct. Moreover, it is difficult to ascertain if the BCMM provides enough protection for people who disclose corruption because $59 \%$ of respondents have no opinion in this regard, $38 \%$ think the BCMM does not provide enough protection and only $2 \%$ think it provides enough protection. The $38 \%$ of respondents who think that BCMM does not provide enough protection could be indicative of BCMM's progress towards the achievement of its good governance strategic objectives for 2011/12. The strategic objectives include the "development of fraud awareness and culture capable of mitigating fraud in a responsible manner" (Buffalo City Metropolitan Municipality, 2011b, p. 3). If most people feel vulnerable as a result of exposing fraud and corruption, then very few will have the courage to risk their lives. This is especially so in light of the death threats the municipal manager and his family received as a result of his fight against corruption and these threats attest to the determination by some individuals to continue with corruption by removing people who prevent it (Weekend Post, 2011; Hollands, 2011). This is not unique to the BCMM as whistle-blowers were victimised in other municipalities such as the Sol Plaatjie Municipality (Gxoyiya, 2011; Sol Plaatjie Municipality, 2012).

Evidently, BCMM measures for preventing fraud and corruption are insufficient because the use of BCMM resources for personal purposes continues. Table 1 shows the extent to which specific resources were used for personal purposes. This happened despite the stipulation in the Local Government Municipal Systems Act (2000) that "a staff member of a municipality may not use, take, acquire, or benefit from any property or asset owned, controlled or managed by the municipality to which that staff member has no right" (p. 118). That being said, 36\% of respondents believe that workers use what does not belong to them without permission from the owners, while $13 \%$ think this does not happen and $51 \%$ are neutral. 
Table 1: Extent to Which Specific Resources are Used for Personal Purposes

\begin{tabular}{|c|c|c|c|c|c|c|}
\hline Resource & 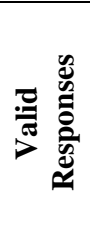 & $\sum^{\tilde{E}}$ & 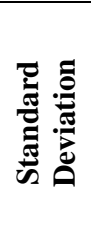 & 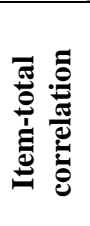 & $\begin{array}{l}=\frac{0}{2} \\
\frac{0}{2} \\
\frac{0}{2}\end{array}$ &  \\
\hline Use of BCMM's vehicles for personal purposes & 315 & 3.62 & 1.23 & 0.81 & 0.84 & $57 \%$ \\
\hline Use of BCMM's phones for personal purposes & 312 & 3.26 & 0.88 & 0.32 & 0.88 & $36 \%$ \\
\hline Use of BCMM's money for personal purposes & 302 & 2.98 & 0.98 & 0.38 & 0.87 & $31 \%$ \\
\hline Use of BCMM's time for personal purposes & 311 & 3.70 & 1.13 & 0.68 & 0.85 & $60 \%$ \\
\hline Use of BCMM's equipment for personal purposes & 308 & 3.64 & 1.16 & 0.73 & 0.85 & $56 \%$ \\
\hline $\begin{array}{l}\text { Use of positional authority in the BCMM to pursue personal } \\
\text { interests }\end{array}$ & 310 & 2.91 & 0.92 & 0.30 & 0.88 & $15 \%$ \\
\hline Deceitful use of leave benefits & 309 & 3.42 & 0.90 & 0.57 & 0.86 & $55 \%$ \\
\hline $\begin{array}{l}\text { Rewards for favours received which are against the BCMM } \\
\text { policies }\end{array}$ & 308 & 3.97 & 1.04 & 0.79 & 0.84 & $81 \%$ \\
\hline Bribery of BCMM workers & 308 & 3.73 & 1.13 & 0.67 & 0.85 & $58 \%$ \\
\hline Delaying decisions in order to pursue personal interests & 309 & 3.35 & 0.86 & 0.61 & 0.86 & $37 \%$ \\
\hline
\end{tabular}

To get the percentages in Table 1, the last two options (to a high extent and to a very high extent) were combined, but the mean, standard deviation, Cronbach alpha, and average inter-item correlation are for all five options in the Likert scale. The mean in Table 1 suggests that many respondents chose the high end of the scale, as the lowest average is 2.91 and the highest is 3.97. Table 1 also shows that according to $81 \%$ of the respondents, BCMM workers accept rewards for favours received which were against BCMM policies. These include getting inside information regarding tenders, and inducements, rewards, gifts, and favours to municipal officials for the purpose of getting a contract. This buttresses the conviction of the BCMM municipal manager that BCMM "is corrupt to its core at an administration and supply chain management level" (Times Live, 2011, p. 1). According to $60 \%$ of respondents, BCMM's time is used for personal purposes, with $55 \%$ of respondents observing that some workers use their leave benefits deceitfully. Deceitful use of leave benefits includes acquisition of fraudulent certificates, and not reporting for duty on account of being sick while in reality they are not. For this reason, Tanzi (1998) emphasises that "not all acts of corruption result in the payment of bribes" (p. 565). For example, a public employee who claims to be sick but goes on vacation is abusing his public position for personal use. Thus, he is engaging in an act of corruption even though no bribe is paid. The rate of absenteeism of BCMM workers is rather high. Although the internationally accepted rate of absenteeism is 3\%, for sick leave only, the BCMM recorded 2.8\%, 3.9\%, and 4.4\% in April, May, and June 2011 respectively (Buffalo City Metropolitan Municipality, 2011a). The council then established the Absenteeism Management Committee, whose responsibility is to monitor the rate of absenteeism, investigate its motivation and propose measures to reduce it. It also researched worker absenteeism (at the time of writing this research report, the results of this study had not yet been made public).

Vehicles, according to $57 \%$ of the respondents, and equipment, according to $56 \%$, are also used for personal purposes, yet the Local Government Municipal Systems Act (2000) forbids this practice. This suggests that one has to dig deeper in order to understand the $69 \%$ of respondents who note that there is a shortage of material to use for doing their jobs. Logically, there is bound to be a shortage of such material if workers use it for personal purposes. The cross-tabulation shows that, of the respondents who think there is enough material for all the workers to use in doing their jobs, $86.36 \%$ think that BCMM workers use BCMM's vehicles for personal purposes. This was established through a combination of respondents who agree and strongly agree on the question on whether there is enough material for all the workers to use in doing their jobs and those who chose the high and the very high extent on whether BCMM workers use BCMM's vehicles for personal purposes. The relationship between the two variables was found to be statistically significant $\left(\mathrm{Chi}^{2}=380.28, \mathrm{df}=16, \mathrm{p}=0.0000\right)$ with Cramér's $\mathrm{V}=0.56$ which indicates that this finding is of large practical significance. The Spearman correlation coefficient ( 0.63$)$ indicates that there is a moderate correlation between thinking that there is enough material for all the workers to use in doing their jobs and the use of BCMM's vehicles for personal purposes. 
Moreover, $31 \%$ of respondents observe that workers use BCMM's money for personal purposes. The crosstabulation shows that, of respondents who think that all BCMM workers can be depended upon to undertake honestly the work assigned to them, 70.58\% believe that BCMM workers used BCMM's money for personal purposes. This was established through a combination of respondents who agree and strongly agree on the question about whether BCMM workers can be depended upon to undertake honestly the work assigned to them and those who chose high extent and very high extent on the question about whether the workers use BCMM's money for personal purposes. The relationship between the two variables was found to be statistically significant $\left(\mathrm{Chi}^{2}=\right.$ 476.22, $\mathrm{df}=16, \mathrm{p}=0.0000$ ) with Cramér's $\mathrm{V}=0.63$ which indicates that this finding is of large practical significance. The Spearman correlation coefficient $(0.57)$ indicates that there is a moderate correlation between thinking that all BCMM workers can be depended upon to undertake honestly the work assigned to them and the use of BCMM's money for personal purposes.

The $37 \%$ of respondents who observed delaying of decisions in order to pursue personal interests could also be referring to the R3.1 million spent on "emergency requisitions" (Nini, 2012, p. 1). The BCMM's supply chain management (SCM) policy suggests that "in the normal course of business, procurement of goods and services are allowed either by way of price quotation or through a competitive bidding process" (Public Safety, 2010, p. 13). However, National Treasury (2011) states that in emergency cases, that is, "cases where immediate action is necessary in order to avoid a dangerous or risky situation or misery" these processes may be dispensed with and procurement done in any manner that is in the best interests of the department or municipality concerned (p. 32). Some respondents suggest that some workers take advantage of this and create emergency cases by delaying procurement decisions in order to procure from their accomplices. Such cases make it impracticable to ensure procurement that is fair, equitable, transparent, competitive and cost-effective as stipulated in article 217(1) of the Constitution because standard procurement processes are bypassed (Buffalo City Metro Municipality, 2010; National Treasury Republic of South Africa, 2004). Emergency cases then make it possible for the selected supplier to charge uncompetitive prices and thereafter share the profits with the official who created the emergency.

The fact that $41 \%$ of respondents hold that all BCMM workers can be depended upon to undertake honestly the work assigned to them needs to be viewed with caution in light of such high level use of BCMM resources for personal purposes. This caution is underscored by the fact that $54 \%$ of respondents think that insincerity is a form of inappropriate job behaviour that occurs in their respective departments. In fact, the cross-tabulation shows that, of the respondents who think all BCMM workers can be depended upon to undertake the work assigned to them honestly, $69.35 \%$ strongly believe that workers use BCMM's vehicles for personal purposes. This was established through a combination of respondents who agreed and strongly agreed on the question about whether BCMM workers can be depended upon to undertake honestly the work assigned to them and those who chose high extent and very high extent on the question about whether the workers used BCMM's vehicles for personal purposes. The relationship between the two variables was found to be statistically significant $\left(\mathrm{Chi}^{2}=517.98, \mathrm{df}=16, \mathrm{p}=0.0000\right)$ with Cramér's $V=0.65$ which indicates that this finding is of large practical significance. However, the Spearman correlation coefficient $(0.12)$ indicates that there is no correlation between the idea that BCMM workers can be depended upon to undertake honestly the work assigned to them and the idea that BCMM workers use BCMM's vehicles for personal purposes.

According to $38 \%$ of respondents, the BCMM views mismanagement of assets like money, vehicles, and telephones as a serious offence; $31 \%$ believe that it does not view it as a serious offence and another $31 \%$ had no opinion one way or the other. Some respondents, however, suggest that if the municipality were serious about its assets, there would not be many employees in acting positions because they strongly believe that this makes the municipality vulnerable by weakening decision-making on inappropriate job behaviour. Apparently, acting staff do not want to jeopardize their chances of permanent employment, and are thus reluctant to take tough decisions. The reverse argument is that people in acting positions could take advantage of the situation and take tough decisions in an effort to prove that they are capable of doing the job to which they should therefore be appointed permanently.

A factor that contributed to thinking that the BCMM does not view mismanagement of its assets as a serious offence is the alleged inefficient treatment of suspension cases. Suspension on full pay and appointment of someone to act in that position means an increase in the municipality's salary expenses because the suspended worker is paid and the one acting has to be paid an acting allowance. These expenses continue until the suspended 
worker is proven guilty or not guilty by a disciplinary committee or court of law. The longer the disciplinary and/or court processes take, the longer the municipality suffers increased salary expenses. It is then not surprising that many respondents (38\%) believe that the BCMM has no effective policy to get rid of unproductive workers, while $28 \%$ are of the view that it does and $33 \%$ prefer to remain neutral. The high percentage of noncommittal responses, though respondents were promised anonymity, could indicate lack of trust due to the political camps that exist at the BCMM.

\section{JOB SATISFACTION}

In addition to the cultivation of appropriate ethics, values, and attitudes to enhance job behaviour and performance, it is clear that more still needs to be done at the BCMM about the work environment. If $37 \%$ of respondents observed that workers like their jobs, 30\% thought they do not and 32\% had no opinion, it means that although many respondents thought workers like their jobs, there is still a significant number who are unhappy. Reasons for the unhappiness must then be investigated and addressed. Some could be related to conflict at work, communication, and job characteristics. If $36 \%$ of respondents felt that their managers manage conflict well, $34 \%$ felt that they do not, and $30 \%$ had no opinion, it means that although many respondents thought managers manage conflict well, a significant number does not think so. Conflict management involves understanding the cause and nature of conflict; therefore, it would be prudent to get to the bottom of this challenge and address it thoroughly. Similarly, $36 \%$ of respondents felt that their jobs had more attractive than unattractive characteristics, $31 \%$ felt that unattractive characteristics dominate, and $33 \%$ had no opinion. Although many respondents (36\%) thought their jobs had more attractive than unattractive characteristics, the $31 \%$ who thought otherwise is significant.

Table 2 through to Table 5 use type of employment (permanent or contract), age, gender, and race to depict three aspects of job satisfaction namely:

1. Workers who feel discouraged from exposing job misbehaviour such as fraud and corruption, because no strong action ever gets taken against the culprits;

2. Workers who are bored at work;

3. Workers who think their jobs have more attractive than unattractive characteristics.

Table 2: Job Satisfaction by Type of Employment (Permanent or Contract)

\begin{tabular}{|l|c|c|c|}
\hline & $\begin{array}{c}\text { Workers who feel discouraged from } \\
\text { exposing job misbehaviour such as fraud and } \\
\text { corruption because no strong action is ever } \\
\text { taken against such behaviour }\end{array}$ & $\begin{array}{c}\text { Workers who are } \\
\text { bored at work }\end{array}$ & $\begin{array}{c}\text { Workers who think their } \\
\text { jobs have more attractive } \\
\text { than unattractive } \\
\text { characteristics }\end{array}$ \\
\hline Permanent & $48.76 \%$ & $40.32 \%$ & $48.21 \%$ \\
\hline Contract & $92.86 \%$ & $0 \%$ & $1.27 \%$ \\
\hline Chi-square & 67.96 & 174.78 & 196.14 \\
Cramér's V & 0.46 (large practical significance) & $\begin{array}{c}0.73 \text { (large } \\
\text { practical } \\
\text { significance) }\end{array}$ & $\begin{array}{c}0.80 \text { (large practical } \\
\text { significance) }\end{array}$ \\
\hline Degrees of freedom & 4 & 4 & .00000 \\
\hline P value & .00000 & & .00000 \\
\hline
\end{tabular}

Table 2 reveals that $92.86 \%$ of the respondents who are temporary and contract workers feel discouraged from exposing job misbehaviour such as fraud and corruption, because no strong action is ever taken against such behaviour. There are fewer $(48.76 \%)$ permanent workers who feel the same. The high rate $(92.86 \%)$ of discouragement among temporary and contract workers could be because many of them hope for permanent employment. Therefore, the notion that there is no strong action taken against fraud and corruption could be seen as compromising their chances of permanent employment. This notion could also be held on account of their observation that finding employment is on the basis of who you know. The hope for permanent employment is corroborated by the fact that no temporary and contract workers admitted to being bored at work. On the contrary, only a very small percentage $(1.27 \%)$ of them thought their jobs had more attractive than unattractive characteristics and most $(96.20 \%)$ chose the 'neither agree nor disagree' option. A significant share $(48.21 \%)$ of permanent workers, however, thought that their jobs had more attractive than unattractive characteristics. 
Of the 344 respondents, $259(75.29 \%)$ were employed on a permanent basis, $6(1.74 \%)$ temporary and 79 $(22.96 \%)$ on contract. The tenure distribution was $<1$ year $=5(1.45 \%), 1-5$ years $=96(27.90 \%), 6-10$ years $=143$ $(41.57 \%), 11-15$ years $=63(18.31 \%), 16-20$ years $=13(3.78 \%), 21-25$ years $=8(2.32 \%), 26-30$ years $=7(2.03 \%)$, $\geq 31$ years $=6(1.74 \%)$, and unspecified $=3(0.87 \%)$. Moreover, the data shows that people in clerical and administrative positions comprise a big share of BCMM workers. These positions include Enquiry Clerks, Natis Clerks, Chief Clerks, Administrative Clerks, Records Clerks, and Senior Clerks.

Table 3: Job Satisfaction By Age

\begin{tabular}{|c|c|c|c|}
\hline & $\begin{array}{c}\text { Workers who feel discouraged from exposing } \\
\text { job misbehaviour such as fraud and } \\
\text { corruption because no strong action is ever } \\
\text { taken against such behaviour }\end{array}$ & $\begin{array}{l}\text { Workers who are } \\
\text { bored at work }\end{array}$ & $\begin{array}{c}\text { Workers who think their } \\
\text { jobs have more attractive } \\
\text { than unattractive } \\
\text { characteristics }\end{array}$ \\
\hline 20-39 years & $86.39 \%$ & $5.79 \%$ & $46.74 \%$ \\
\hline 40-49 years & $13.86 \%$ & $73.53 \%$ & $8.52 \%$ \\
\hline 50+ years & $50 \%$ & $34.29 \%$ & $60 \%$ \\
\hline Chi-square & 240.39 & 229.27 & 222.87 \\
\hline Cramér's V & 0.61 (large practical significance) & $\begin{array}{c}0.59 \text { (large practical } \\
\text { significance) }\end{array}$ & $\begin{array}{c}0.61 \text { (large practical } \\
\text { significance) }\end{array}$ \\
\hline $\begin{array}{l}\text { Degrees of } \\
\text { freedom }\end{array}$ & 8 & 8 & 8 \\
\hline P value & .00000 & .00000 & .00000 \\
\hline
\end{tabular}

The age distribution profile of the respondents was 20-29 years $=17(4.94 \%), 30-39$ years $=183(53.19 \%)$, $40-49$ years $=105(30.52 \%), 50-59$ years $=31(9.01 \%), 60$ years and above $=7(2.03 \%)$, and unspecified $=1$ $(0.29 \%)$. Table 3 reveals that $86.39 \%$ of respondents in the $20-39$ years cohort felt discouraged from exposing job misbehaviour because no strong action is ever taken against such behaviour. However, $13.86 \%$ in the $40-49$ years cohort and 50\% in the 50+ years cohort felt the same. The high rate of discouragement in the 20-39 years cohort could be because many of them are new in the labour market and, for the first time, are experiencing the differences between what they learnt at school or university and how the labour market operates. For instance, while school or university may have inculcated meritocratic values (e.g., the harder you work, the higher you progress career wise and the more you earn), the reality may be that factors such as who you know, political affiliation, and laws such as the Employment Equity Act (1998) which gives preference to candidates from designated groups, may play a role. This is supported by the fact that only $5.79 \%$ of respondents in the 20-39 years cohort admitted to being bored at work as opposed to $73.53 \%$ who are bored in the $40-49$ years and $34.29 \%$ in the $50+$ years cohorts. However, most of those who thought that their jobs had more attractive than unattractive characteristics are in the 50+ years cohort, followed by $46.74 \%$ in the $20-39$ years and $8.52 \%$ in the $40-49$ years cohorts.

Table 4: Job Satisfaction by Gender

\begin{tabular}{|l|c|c|c|}
\hline & $\begin{array}{c}\text { Workers who feel discouraged from exposing } \\
\text { job misbehaviour such as fraud and corruption } \\
\text { because no strong action is ever taken against } \\
\text { such behaviour }\end{array}$ & $\begin{array}{c}\text { Workers who think their } \\
\text { Workers who are } \\
\text { bored at work }\end{array}$ & $\begin{array}{c}\text { jobs have more attractive } \\
\text { than unattractive } \\
\text { characteristics }\end{array}$ \\
\hline Male & $50 \%$ & $43.14 \%$ & $9.84 \%$ \\
\hline Female & $77.04 \%$ & $8.14 \%$ & $81.82 \%$ \\
\hline Chi-square & 31.68 & 155.90 & 183.41 \\
\hline $\begin{array}{l}\text { Cramér's } \\
\text { V }\end{array}$ & 0.31 (medium practical significance) & $\begin{array}{c}0.69 \text { (large practical } \\
\text { significance) }\end{array}$ & $\begin{array}{c}0.78 \text { (large practical } \\
\text { significance) }\end{array}$ \\
\hline $\begin{array}{l}\text { Degrees of } \\
\text { freedom }\end{array}$ & 4 & 4 & 4 \\
\hline P value & .00000 & .00001 & .00000 \\
\hline
\end{tabular}

The gender distribution profile of the respondents was $209(60.75 \%)$ males, 134 (38.95\%) females, and 1 $(0.29 \%)$ unspecified. From Table 4, we learn that $77.04 \%$ of female respondents felt discouraged from exposing job misbehaviour such as fraud and corruption, because no strong action is ever taken against it. At 50\%, fewer male respondents felt the same. The high rate of discouragement among female respondents could be in support of Rivas's (2008) research finding that "women are indeed less corrupt than men." (p. 1). However, males (43.14\%) 
seem more bored at work than their female $(8.14 \%)$ counterparts. While some studies suggest that "gender is not matter for boredom at work" (Sohail, Ahmad, Tanveer, \& Tariq, 2012, p. 923), others argue "that males are more boredom prone than females" (Vodanovich, Kass, Andrasik, Gerber, Niederberger, \& Breaux, 2011, p. 2). Additionally, most $(81.82 \%)$ female respondents thought that their jobs have more attractive than unattractive characteristics as opposed to the few $(9.84 \%)$ males who thought the same.

Table 5: Job Satisfaction by Race

\begin{tabular}{|l|c|c|c|}
\hline & $\begin{array}{c}\text { Workers who feel discouraged from exposing } \\
\text { job misbehaviour such as fraud and } \\
\text { corruption because no strong action is ever } \\
\text { taken against such behaviour }\end{array}$ & $\begin{array}{c}\text { Workers who are } \\
\text { bored at work }\end{array}$ & $\begin{array}{c}\text { Workers who think their } \\
\text { jobs have more attractive } \\
\text { than unattractive } \\
\text { characteristics }\end{array}$ \\
\hline Black & $48.44 \%$ & $41.51 \%$ & $12.56 \%$ \\
\hline White & $90 \%$ & $4.44 \%$ & $89.66 \%$ \\
\hline Chi-square & 54.60 & 207.65 & 182.90 \\
\hline Cramér's V & 0.42 (medium practical significance) & $\begin{array}{c}0.81 \text { (large practical } \\
\text { significance) }\end{array}$ & $\begin{array}{c}0.79 \text { (large practical } \\
\text { significance) }\end{array}$ \\
\hline $\begin{array}{l}\text { Degrees of } \\
\text { freedom }\end{array}$ & 4 & 4 & 4 \\
\hline P value & .00000 & .00000 & .00000 \\
\hline
\end{tabular}

The race distribution profile of the respondents was 237 (68.89\%) Blacks, 90 (26.16\%) Whites, 4 (1.16\%) Asians, 11 (3.19\%) Coloureds, and $2(0.58 \%)$ Other. From Table 5, we learn that $90 \%$ of White respondents felt discouraged from exposing job misbehaviour because no strong action is ever taken against such behaviour. At 48.44\%, fewer Black respondents felt the same. The researcher could not find studies on the attitude of Blacks in relation to Whites concerning fraud and corruption. However, Hyslop (2005) observed that "attitudes toward corruption in the post-1994 political leadership were certainly affected by the ANC's 180-degree shift in ethos from advocacy of an austere socialism in the mid-1980s to the celebration of the self-enrichment of a new black elite by the mid-1990s" (p. 786) Few (4.44\%) White respondents admitted to being bored at work, as compared to $41.51 \%$ of Black respondents with a similar admission. Similarly, most (81.82\%) White respondents thought that their jobs have more attractive than unattractive characteristics, while few (12.56\%) Black respondents thought the same. There are obvious reasons for jobs to be attractive or unattractive. These need to be investigated and addressed properly. The qualitative responses reveal that the unattractive parts of working at the BCMM include tensions as a result of the two centres of power, unequal treatment of employees, remuneration, corruption, delays in organogram review, job insecurity, and municipal instability.

Furthermore, many workers are not pleased with communication at the BCMM as $39 \%$ of respondents believe that there is no regular communication between workers and management about work-related issues, though $32 \%$ felt that there is and 29\% were neutral. Apparently, workers whose responsibilities do not involve using a computer and having access to the internet get fewer communiqués from the management than those with computer access. For them, the message has to be relayed by the line manager and sometimes this means that they get the communiqués late or not at all. This is because some, like electricians and plumbers, work outside municipal premises and only report at the depot in the morning and afternoon when they come back from the field.

Regarding capacity, although most respondents (67\%) noted that there is a staff shortage in relation to the responsibilities of their respective departments, $30 \%$ admitted to being bored at work. The cross-tabulation shows that, of the respondents who felt bored at work, $79.56 \%$ thought there are too many workers in relation to the responsibilities of their departments. This was established through a combination of respondents who agreed and strongly agreed on whether they felt bored at work and those who chose high extent and very high extent on whether there are too many workers in relation to the responsibilities of their departments. The relationship between the two variables was found to be statistically significant $\left(\mathrm{Chi}^{2}=436.27, \mathrm{df}=16, \mathrm{p}=0.0000\right)$ with Cramér's $\mathrm{V}=0.60$ which indicates that this finding is of large practical significance. However, the Spearman correlation coefficient $(0.37)$ indicates that there is a moderate correlation between feeling bored at work and the number of workers in relation to the responsibilities in the respective departments. It is rather difficult to reconcile the staff shortage claim with boredom. The bored workers could be uninterested in their jobs or idling with nothing much to do, which would echo the view that the public service labour force is bloated (Bowling, 2007; Sol Plaatje Municipality, 2012; 
National Treasury, 2011; Child, 2011). However, 43\% admitted that they are not bored and 27\% had no opinion on this issue.

Despite the claim of boredom, $36 \%$ of respondents believe that the BCMM is the best employer to work for, while $34 \%$ disagreed and $30 \%$ had no opinion. The cross-tabulation shows that, of the respondents who felt bored at work, $78.12 \%$ thought the BCMM is the best employer to work for. This was established through a combination of respondents who agreed and strongly agreed on the question about feeling bored at work and those who agreed and strongly agreed about whether the BCMM is the best employer to work for. The relationship between the two variables was found to be statistically significant $\left(\mathrm{Chi}^{2}=608.83, \mathrm{df}=16, \mathrm{p}=0.0000\right)$ with Cramér's $\mathrm{V}=0.69$ which indicates that this finding is of large practical significance. However, the Spearman correlation coefficient $(0.24)$ indicates that there is no correlation between feeling bored at work and thinking that the BCMM is the best employer to work for.

\section{CONCLUSION}

The continuing inappropriate job behaviour and performance in organizations such as the BCMM challenges the assertion that formal education alone translates to fewer social problems. The evidence of inappropriate job behaviour and performance of those with formal education makes the achievement of the functionalists' goals for education doubtful, specifically the economic development and common good goals. The evidence from this study also reveals the weakness of the functionalist theory which focuses on the positive contributions that education makes to society and overlooks its negative contributions and limitations. The BCMM workers' inappropriate job behaviour and performance are a serious setback for functionalist claims about education as even some of those appointed on academic merit do not reflect appropriate ethics, attitudes, and values. A thorough diagnosis of job performance problems is very important because these challenges involve compromised service quality and this does not augur well for the sustainability of the BCMM's metropolitan status. Some of the workers' responsibilities require not so much formal education qualifications, but rather, any applicable skill in addition to an ethical and moral approach to undertaking job responsibilities. By and large, the unquestioning acceptance of the assumption that the skills shortage is responsible for inappropriate workers' job performance and behaviour is discredited by the evidence of skilled personnel who exercise their responsibilities in a manner that undermines their occupational requirements. Therefore, it is imperative to realise that the narrow conception of skills that privileges job-specific capabilities is not enough for cultivating a workforce with appropriate job behaviour and performance practices. The seriousness of the municipal responsibility necessitates efficacious application of management principles, because the growth and development of every economy hinge on how resources are judiciously managed and increased. Therefore, the application of broad skills and effective management practices is crucial to close the gaps that enable the perpetuation of inappropriate job behaviour and performance in BCMM systems. Importantly, the broad skills concept does not place importance on one of its components at the expense of the others, as does the positivist model which raises the importance of schooling above the other factors contributing towards enabling workers to discharge their responsibilities appropriately. The many determinants of job behaviour and performance render labour (ability to work) nebulous. This poses challenges in ascertaining the skills status quo, especially in light of the notion of broad skills. Further research is required on this subject to establish the need for broad skills in developing the competencies of employees in any organisation.

\section{AUTHOR INFORMATION}

Prakash Singh is a professor at the Nelson Mandela Metropolitan University in Port Elizabeth, South Africa. He is an NRF rated researcher and a Fulbright scholar. His niche research areas of publication are organizational behaviour and social psychology. Professor Singh is the author of Innovative Strategies to Develop Better Schools and co-author of Principal Leadership. He has also published widely in peer-reviewed journals and has presented numerous papers at international conferences. E-mail: Prakash.Singh@nmmu.ac.za (Corresponding author)

Thembinkosi Twalo is currently employed as a Chief Researcher at the Human Sciences Research Council. His highest qualification is a $\mathrm{PhD}$ degree which he obtained from the Nelson Mandela Metropolitan University in Port Elizabeth, South Africa. His research focus is on job behaviour and performance. He has published several articles in peer reviewed journals and has presented several papers at international conferences. E-mail: ttwalo@hsrc.ac.za 


\section{REFERENCES}

1. Agrawal, A., \& Cooper, T. (2007, March). Corporate governance consequences of accounting scandals: Evidence from top management, $\mathrm{CFO}$ and auditor turnover. Retrieved from http://bama.ua.edu/ aagrawal/MT.pdf

2. Almquist, E. M., Chafetz, J. S., Chance, B. J., \& CorderBolz, J. (1978). Sociology: Women, men, and society. Minessota: West Publishing Company.

3. Badat, S. (2009). Beyond the obsession with skills and towards a discourse of knowledge, skills and attitudes. (ECSECC Working Paper, Series 8).

4. Badenhorst, J. (2012). In focus: Buffalo City is definitely a metro and is viable. Retrieved from http://www.dispatch.co.za/in-focus-buffalo-city-is-definitely-a-metro-and-is-viable/

5. Benya, Z. (2011). The effectiveness of poverty alleviation initiatives in the Buffalo City Metropolitan Municipality. (Unpublished MA dissertation). Port Elizabeth, South Africa: Nelson Mandela Metropolitan University.

6. Bourdieu, P. (1997). The forms of capital. In A. H. Halsey, H. Lauder, P. Brown, \& A. S. Wells (Eds.), Education: Culture, economy and society. New York: Oxford University Press.

7. Bowling, N. A. (2007). Is the job satisfaction-job performance relationship spurious? A meta-analytic examination. Journal of Vocational Behavior, 71, 167-185.

8. Bryant, L. (2012). Functionalism and education. Retrieved from http://www.historylearningsite.co.uk/ functionalsim_education.htm

9. Buffalo City Metro Municipality. (2010). Draft Integrated Development Plan 2011-2016. Retrieved from www.buffalocity.gov.za/municipality/idp11/sectionf.pdf

10. Buffalo City Metropolitan Municipality. (2011a). KPA Achievement Report. Retrieved from http://www.buffalocity.gov.za/municipality/annual_report10-11/final/prt2_kpa_report.pdf

11. Buffalo City Metropolitan Municipality. (2011b). Service Delivery and Budget Implementation Plan for 2011/2012. Retrieved from http://www.google.co./

12. Buffalo City Metropolitan Municipality. (2012). Vacancies. Retrieved from http://www.buffalocity.gov.za/ municipality/vacancies2012/vacancies_12march12.pdf

13. Business Dictionary. (2013). Nonparametric method. Retrieved from http://www.businessdictionary.com/ definition/nonparametric-method.html

14. Cahn, S. M. (1970). The philosophical foundations of education. New York: Harper and Row Publishers.

15. Child, K. (2011). Telkom buyout could be a good Korea move. Retrieved from http://mg.co.za/article/201110-14-telkom-buyout-could-be-a-good-korea-move

16. Cliff, N. (2012). Three major perspectives in sociology. Retrieved from http://www.cliffsnotes.com/ study_guide/topicArticleId-26957,articleId-26837.html

17. Coetzer, P. (2009). Service delivery falls prey to political expediency: Minister to put a turnaround strategy on the table. Retrieved from http://www.servicepublication.co.za/index.php/magazine/other/175-servicedelivery-falls-prey-to-political-expediency

18. Creswell, J. W., \& Plano-Clark, V. L. (2007). Designing and constructing mixed research methods. London: Thousand Oaks.

19. Durkheim, E. (1977). The evolution of educational thought. London: Routledge.

20. Employment Equity Act No. 55 of 1998. Department of Labour: Republic of South Africa.

21. Gerber, M. (2010). Sociology. Toronto: Pearson.

22. Gichure, C. W. (2000). Happiness through human work. Retrieved from http://www.bu.edu/wcp/ Papers/Acti/ActiGich.htm

23. Goss, D. (1994). Principles of human resource management. London: Routledge.

24. Greenburg, J. (2002). Who stole the money, and when? Individual and situational determinants of employee theft. Organisational Behaviour and Human Decision Processes, 89(1), 985-1004.

25. Guerrero, L. (2005). Sociology and the study of social problems. Retrieved from www.sagepub.com/upmdata/4617_Leon_Guerrero_Chapter_1.pdf

26. Gxoyiya, A. (2011). Whistleblowers victimised in Sol Plaatjie Municipality. Retrieved from http://www.politicsweb.co.za/politicsweb/view/politicsweb/en/page72308?oid=269695\&sn=Marketingweb + detail\&pid=90389 
27. Hanushek, E., \& Woessmann, L. (2008). The role of cognitive skills in economic development. Journal of Economic Literature, 46, 607-668.

28. Haralambos, M., \& Heald, R. (1985). Sociology: Themes and perspectives. London: Bell \& Hyman.

29. Hollands, B. (2011). Meet Buffalo City's corruption buster. Retrieved from: http://theweekendpost.com/ tag/andile-fani/

30. Hyslop, J. (2005). Political corruption: Before and after Apartheid. Journal of Southern African Studies, 31(4), 773-789.

31. Investopedia. (2013). Nonparametric statistics. Retrieved from http://www.investopedia.com/terms/n/ nonparametric-statistics.asp

32. Labaree, D. F. (2008). The winning ways of a losing strategy: Educationalizing social problems in the United States. Educational Theory, 58(4), 447-460.

33. Local Government Handbook. (2012). Buffalo City Metropolitan Municipality (BUF). Yes Media.

34. Local Government Municipal Systems Act No. 32 of 2000. Cape Town: Government Gazette.

35. Mawonga, T. A. (2012). A critical analysis of the applicability of the King III in the local government sphere - A case of the Buffalo City Metropolitan Municipality in the Eastern Cape from 2009-2011. (Unpublished MA dissertation). Alice: University of Fort Hare.

36. Moore, J. W., \& Moore, B. M. (1982). Social problems. Englewood Cliffs, N.J: Prentice-Hall, Inc.

37. Municipal Structures Act No. 117 (1998). Retrieved from http://www.info.gov.za/view/ DownloadFileAction?id=70652

38. My Market Research Methods. (2012). Types of data \& measurement scales: Nominal, ordinal, interval and ratio. Retrieved from http://www.mymarketresearchmethods.com/types-of-data-nominal-ordinalinterval-ratio/

39. National Treasury. (2011). Local Government Budgets and Expenditure Review: 2006/07 - 2012/13. Pretoria: National Treasury.

40. National Treasury Republic of South Africa. (2004). Supply Chain Management: A Guide for Accounting Officers / Authorities. Retrieved from www.environment.gov.za/sites/default/.../accountingofficer _scmguide.pdf

41. Naugle, D. (2001). Plato's Republic. Retrieved from http://www3.dbu.edu/naugle/pdf/institute_handouts/ plato/plato_aristotle_notes.pdf

42. Nini, A. (2012). BCM wastes R150m in year. Retrieved from:http://www.dispatch.co.za/bcm-wastesr150m-in-year/

43. Nombembe, T. (2013). Consolidated general report on the audit outcomes of Local Government 2011-12. Auditor-General. Pretoria.

44. Public Protector South Africa. (2012). Report of the Public Protector on an investigation into allegations of a breach of the Executive Ethics Code by the Minister of Cooperative Governance and Traditional Affairs, Mr Sicelo Shiceka, MP. Retrieved from: http://www.pprotect.org/library/investigation_report/Shiceka\%20 Report-\%20Final\%20version\%207-signed.pdf

45. Public Safety. (2010). SCM policy: Public safety. Retrieved from http://www.nwpg.gov.za/public_safety/ PSCircular_1.html

46. Rivas, F.M. (2008). An experiment on corruption and gender. Mimeo: University of Granada.

47. SALGA. (2011). Guideline document on the roles and responsibilities of councillors, political structures and officials. Retrieved from http://www.salga.org.za/pages/Knowledge--Hub/Guidelines-forMunicipalities

48. Singh, P. (2011). SWEAT analysis to determine organisational effectiveness. In W. H. Jonathan (Ed.), Examining job satisfaction: Causes, outcomes and comparative differences. Sydney: Common Ground.

49. Sohail, N., Ahmad, B., Tanveer, Y., \& Tariq, H. (2012). Workplace boredom among university faculty members in Pakistan. Interdisciplinary Journal of Contemporary Research in Business, 3(10), 919-925.

50. Sol Plaatjie Municipality. (2012). Integrated Development Plan (IDP) Five Year Plan 2012/2013 2016/2017.

51. Tanzi, V. (1998). Corruption around the world causes, consequences, scope, and cures. IMF Staff Papers, 45(4), 559-594.

52. Times Live. (2011). We're paying dearly for ANC's cadre deployment policy. Retrieved from http://www.timeslive.co.za/opinion/editorials/2011/12/08/we-re-paying-dearly-for-anc-s-cadredeployment-policy 
53. van Heerden, A. (2010). Curbing a global phenomenon. Retrieved from http://www.accountancysa.org.za/ resources/ShowItemArticle. asp? ArticleId=1941\&Issue=1092

54. Vodanovich, S. J., Kass, S. J., Andrasik, F., Gerber, W. D., Niederberger, U., \& Breaux, C. (2011). Culture and gender differences in boredom proneness. North American Journal of Psychology, 13(2), 221-230

55. Weekend Post. (2011, April 23). Meet Buffalo City's corruption buster. Retrieved from http://theweekendpost.com/tag/east-london/ 
NOTES 